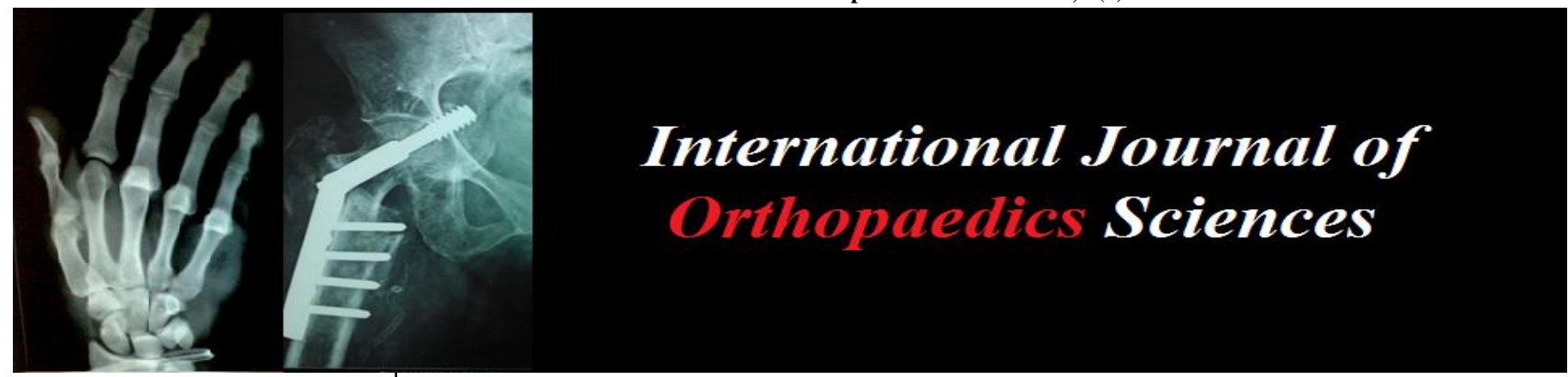

ISSN: $2395-1958$

IJOS 2018; 4(3): 74-77

(C) 2018 IJOS

www.orthopaper.com

Received: 15-05-2018

Accepted: 16-06-2018

Dr. Shivraj Satish Konde Associate Professor, Dept. of Orthopaedics, MIMER, Medical College Talegaon Dabhade, Pune, Maharashtra, India

Dr. Santosh Shridhar Borkar

Professor, Dept. of Orthopaedics, MIMER Medical College Talegaon Dabhade, Pune,

Maharashtra, India

Dr. Sidheshwar Thosar

Resident, Dept. of Orthopaedics, MIMER Medical College

Talegaon Dabhade, Pune,

Maharashtra, India

Dr. Nitinkumar Kanode Dept. of Orthopaedics, MIMER Medical College, Talegaon, Dabhade, Pune, Maharashtra, India

\section{A comparative study of functional outcome of extra articular fracture distal end radius with closed reduction and traditional cast immobilization versus closed reduction with Kapandji's pinning technique}

\author{
Dr. Shivraj Satish Konde, Dr. Santosh Shridhar Borkar, Dr. Sidheshwar \\ Thosar and Dr. Nitinkumar Kanode
}

DOI: $\underline{\text { https://doi.org/10.22271/ortho.2018.v4.i3b.15 }}$

\begin{abstract}
Introduction: Distal end radius fracture account for about 16-18\% of all upper limb injuries. Various methods of closed reduction coupled with additional fixation methods have been claimed to give better results. One of these methods is Kapandji's intrafocal pinning technique. We decided to carry out this study for comparison of traditional cast immobilization versus closed reduction with Kapandji intrafocal pinning technique

Material and methods: A randomized prospective comparative study was carried out in orthopaedic department from 2011 July to 2016 June. 30 patients were subjected to closed reduction and cast and 30 were subjected to closed reduction and intrafocal pinning technique. Intrafocal pinning technique under $\mathrm{C}$ Arm guidance and GA, closed reduction was achieved wherever possible. If inadequate reduction was obtained, even then intrafocal wiring technique can be used for obtaining reduction also. 2 wire technique is commonly used. They were followed up at 1,2,4,6 and 12 weeks, radiologically and clinically.

Results: In the cast group, mean age in years was 62.16 and in the intrafocal pinning group mean age in years was 63.43 years $(\mathrm{P}=0.6097)$. Finger stiffness in 4 cases $(13 \%)$ in cast group and 2 cases $(7 \%)$ in pinning group. Sudeck's dystrophy was seen in 4(13\%) cases in cast group and 3(10\%) cases in pinning group. Pin tract infection was seen in $4(13 \%)$ patients in pinning group. Mean loss of radial length in cast group was $6.83 \mathrm{~mm}$ and Intrafocal pinning group was $3.8 \mathrm{~mm}$ (P value was $<0.0003)$. In our study, we got significant difference in range of motion, VAS scores, loss of radial length, Saito chart, Lindstrom's criteria results of both groups.

Conclusion: Intrafocal pinning technique of Kapandji is superior modality of treatment for fracture distal end radius which are minimally comminuted, without intra-articular extension and grossly unstable as compared to closed reduction and casting technique.
\end{abstract}

Keywords: Intrafocal, Kapandji’s technique, distal radius, fracture

\section{Introduction}

Distal end radius fracture account for about $16-18 \%$ of all upper limb injuries ${ }^{[1]}$. This fracture has the potential to devastate hand function if not treated properly. Usual plaster cast method gives less than satisfactory results in about 30-35\% patients and deformity in about $60-65 \%$ patients ${ }^{[2]}$. Hence, various methods of closed reduction coupled with additional fixation methods have been claimed to give better results ${ }^{[3,4]}$. One of these methods is Kapandji's intrafocal pinning technique ${ }^{[5]}$. As this fracture till today remains a difficult problem to manage, we decided to carry out this study for comparison of traditional cast immobilization versus closed reduction with Kapandji intrafocal pinning technique in elderly patients. We aimed to evaluate movements, grip strength, postoperative infection, deformity, disability, pain etc in both treatment groups.

Material and methods

A randomized prospective comparative study was carried out in orthopaedic department of Bharati Vidyapeeth Medical College, Pune and MIMER Medical College, Pune, from 2011

\section{Dr. Santosh Shridhar Borkar} Professor, Dept. of Orthopaedics, MIMER Medical College Talegaon Dabhade, Pune, Maharashtra, India 
July to 2016 June. After local ethical committee approval, informed consent was obtained from 60 patients aged 50 and above with stable, displaced lower end radius extra articular fracture without gross comminution.

Exclusion criteria were displaced fractures older than 21 days, gross osteoporosis, intra articular fractures, severe comminution, fractures with congenital or other forearm anomalies, history of previous wrist or forearm fractures. 30 patients were subjected to closed reduction and cast and 30 were subjected to closed reduction and intrafocal pinning technique.

Under GA, closed reduction of fracture lower end radius was achieved by Agee's maneouvre under $\mathrm{C}$ arm guidance and below elbow cast was given. For intrafocal pinning technique under $\mathrm{C}$ Arm guidance and GA, closed reduction was achieved wherever possible. If inadequate reduction was obtained, even then intrafocal wiring technique can be used for obtaining reduction also. Under $\mathrm{C}$ arm guidance 1 to $1.5 \mathrm{~mm} \mathrm{~K}$ wire is passed perpendicular to the fracture at fracture site but not through the distal fragment. Then, wire is angled into proximal fragment across its 2 cortices to pry the distal fragment into optimal position by intrafocal wiring technique. 2 wire technique is commonly used. Position of 2 wires are one dorsal (from dorsal ulnar side) and one lateral (from volar radial side). Theoretically, it can be combined with external fixation as pins by itself do not provide rigid fixation but we did not prefer to combine as we wanted to know results of only pinning technique and, we had excluded gross osteoporosis and comminution cases (greater than $50 \%$ off metaphyseal diameter) in whom fracture fragments can slide along the pin.

Both $\mathrm{K}$ wires were bent and cut, and dressing was done. Limb elevation was given along with intravenous antibiotics, and analgesics and calcium supplementation was given. Antibiotics were not given in only cast group. Patients were discharged after 48 hours. They were followed up at 1, 2, 4, 6 and 12 weeks, radiologically and clinically.

VAS scale, Saito charts for deformity and tenderness, Lindstrom's criteria for anatomical end result and Lindstrom's criteria for functional end result was noted for each fracture.

Statistical analysis - Results were analysed using unpaired student's t-test using XLSTAT software.

\section{Pre op xrays}
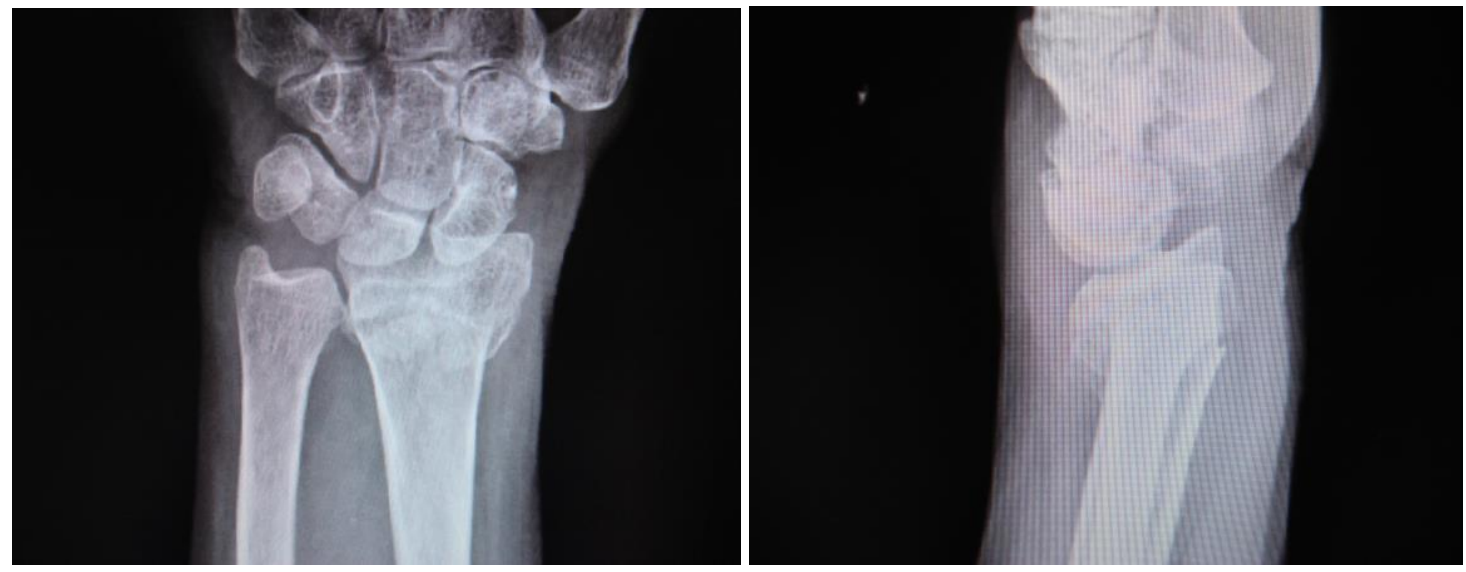

Post op xrays

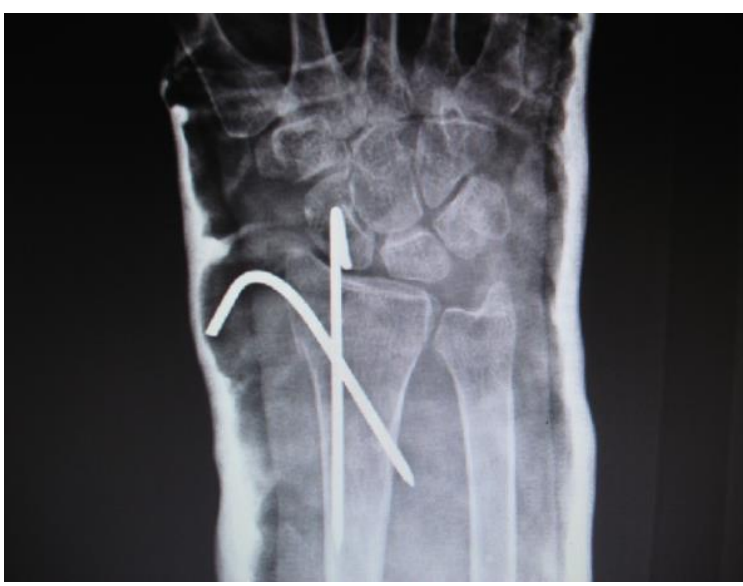

\section{Results}

In the cast group, mean age in years was 62.16 and in the intrafocal pinning group mean age in years was 63.43 years. $\mathrm{P}=0.6097$

Table 1: Gender frequency.

\begin{tabular}{|c|c|c|c|c|}
\hline & Cast Group & Pinning Group & Total & Percentage \\
\hline Male & 12 & 07 & 19 & $31.66 \%$ \\
\hline Female & 18 & 23 & 41 & $68.33 \%$ \\
\hline
\end{tabular}

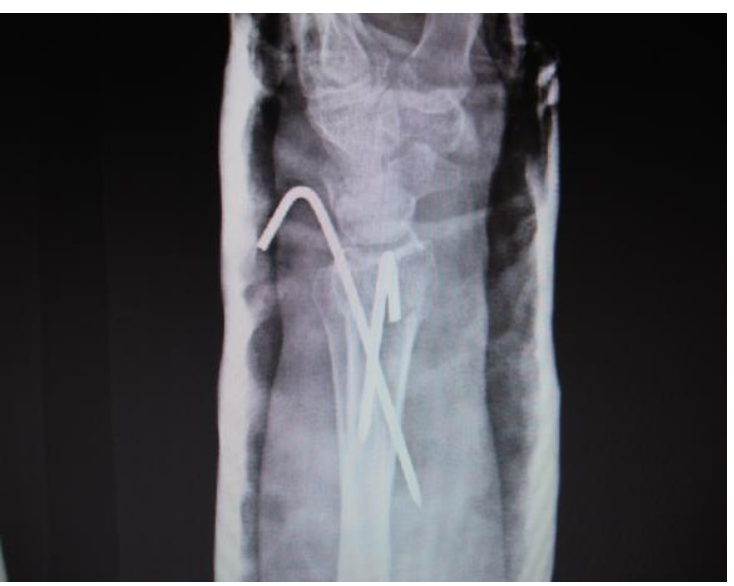

Visual analog scale (VAS) VAS was 5.6 in the cast group. VAS was 4.7 in the pinning group. $\mathrm{P}=0.007$

Table 2: Saito score

\begin{tabular}{|c|c|c|}
\hline & Cast Group & Pinning Group \\
\hline Excellent & $8(26.67 \%)$ & $15(50 \%)$ \\
\hline Good/Fair & $22(73.33 \%)$ & $15(50 \%)$ \\
\hline
\end{tabular}


Table 3: Range of motion

\begin{tabular}{|c|c|c|c|c|}
\hline & Dorsiflexion & Palmar Flexion & Pronation & Supination \\
\hline Cast group & 63.33 & 55.83 & 63 & 66.5 \\
\hline Pinning group & 69.66 & 64.83 & 64.83 & 69.33 \\
\hline $\mathrm{P}$ value & $\mathrm{P}<0.0001$ & $\mathrm{P}<0.0001$ & $\mathrm{P}=0.1$ & $\mathrm{P}=0.007$ \\
\hline
\end{tabular}

This table depicts range of motion in both groups.

Complications were noted in both groups as follows-

a) Finger stiffness in 4 cases $(13 \%)$ in cast group and 2 cases $(7 \%)$ in pinning group.

b) Sudeck's dystrophy was seen in $4(13 \%)$ cases in cast group and 3(10\%) cases in pinning group.

c) Pin tract infection was seen in $4(13 \%)$ patients in pinning group.

d) Osteoarthritis was seen in 6(20\%) patients in cast group and $3(10 \%)$ patients in pinning group.

Table 4: Lindstrom's criteria for anatomical end results

\begin{tabular}{|c|c|c|}
\hline & Cast Group & Pinning Group \\
\hline Grade I & $1(3.33 \%)$ & $17(56.67 \%)$ \\
\hline Grade II & $11(36.67 \%)$ & $6(20 \%)$ \\
\hline Grade III & $14(46.67 \%)$ & $5(16.67 \%)$ \\
\hline Grade IV & $4(13.33 \%)$ & $2(6.66 \%)$ \\
\hline
\end{tabular}

Table 5: Lindstrom's criteria for functional end result

\begin{tabular}{|c|c|c|}
\hline & Cast Group & Pinning Group \\
\hline Excellent & $07(23 \%)$ & $21(70 \%)$ \\
\hline Good & $23(77 \%)$ & $09(30 \%)$ \\
\hline
\end{tabular}

Mean loss of radial length in cast group was $6.83 \mathrm{~mm}$ and Intrafocal pinning group was $3.8 \mathrm{~mm}$. P value was $<0.0003$

\section{Discussion}

Distal end radius fractures treated by various methods continue to give unpredictable results. Various treatment methods generally used are closed reduction and cast, percutaneous pinning fixation, external fixation alone or along with percutaneous $\mathrm{K}$ wires, open reduction and plating, etc ${ }^{[4]}$. Heightened awareness of the complexity of distal end radius fractures has stimulated a growing interest and promoted new ideas regarding their optimal management. Kapandji's intrafocal pinning techniques are an attempt to bridge the therapeutic gap between external fixators and pure casting alone ${ }^{[6,7]}$. External fixators and plating though have a role in treatment of some highly displaced and comminuted unstable distal end radius fractures, many without gross displacement or comminution may be adequately treated with less complicated and intrusive methods ${ }^{[6,7,8]}$.

External fixation can result in stiffness of wrist and fingers in few cases which does not occur with intrafocal pinning technique ${ }^{[9]}$. Kapandji's intrafocal pinning technique is such a technique in which $2 \mathrm{~K}$ wires one dorsal and one lateral help in reduction of fracture and also maintain reduction and length of radius $[9,10]$. Additionally, with intrafocal pinning there is less soft tissue disruption as compared to open reduction and plating which is claimed to give accurate reduction and stable fixation, compared to closed reduction and percutaneous $\mathrm{K}$ wire fixation. It has distinct advantage over conventional $\mathrm{K}$ wire fixation in which this advantage of indirect reduction of fracture is not there ${ }^{[10]}$.

In our study, we got significant difference in range of motion, VAS scores, loss of radial length, Saito chart, Lindstrom's criteria results of both groups. Only significant complication was pin tract infection which resolves after $\mathrm{K}$ wire removal.
We did not observe significant redisplacement after pin removal. Thus our study is giving comparable results like other studies in literature using intrafocal technique of pinning like "Kapandji A" et al, "Dowdy PA" et al, "Rosenthal" et al, "Brady" et al, "S N Parikh" et al which claim good results with intrafocal pinning technique ${ }^{[11,12,13,14]}$.

\section{Conclusion}

Intrafocal pinning technique of Kapandji is superior modality of treatment for fracture distal end radius which are minimally comminuted, without intra-articular extension and grossly unstable as compared to closed reduction and casting technique.

\section{References}

1. Rockwood CA Jr, David Livean P. Fractures in adults 5th edition. 2001; 2:815-863.

2. Campbell's operative orthopaedics 8th edition. 1991; 2:1046-1050.

3. Jupiter JB. fractures of the distal end of the radius. J Bone Joint Surg. 1991; 3A:461-467.

4. Cooney WP. Management of Colles' fractures. Journal of Hand Surgery. 1989; 14(2):137-139.

5. Kapandji A. Internal fixation by double intrafocal plate. Functional treatment of non articular fractures of the lower end of the radius (author's transl). In Annales de chirurgie. 1976; 30(11-12):903-908.

6. Kreder HJ, Agel J, McKee MD, Schemitsch EH, Stephen D, Hanel DP. A randomized, controlled trial of distal radius fractures with metaphyseal displacement but without joint incongruity: closed reduction and casting versus closed reduction, spanning external fixation, and optional percutaneous K-wires. Journal of orthopaedic trauma. 2006; 20(2):115-121.

7. Kapandji A. Intra-focal pinning of fractures of the distal end of the radius 10 years later. Annales de chirurgie de la main: organe officiel des societes de chirurgie de la main. 1987; 6(1):57-63.

8. Arora R, Gabl M, Gschwentner M, Deml C, Krappinger D, Lutz M. A comparative study of clinical and radiologic outcomes of unstable colles type distal radius fractures in patients older than 70 years: nonoperative treatment versus volar locking plating. Journal of orthopaedic trauma. 2009; 23(4):237-242.

9. Junkin NH. External fixation colle's fracture journal of hand surgery. 1989; 14B:149-154.

10. Stoffelen DVC, Broos PL. Kapandji pinning or closed reduction for extra-articular distal radius fractures. Journal of Trauma and Acute Care Surgery. 1998; 45(4):753-757.

11. Brady $\mathrm{O}$ et al. The unstable distal radial fracture one year post Kapandji intrafocal pinning. Injury. 1999; 30(4):251-255.

12. Dowdy Paul A et al. Intrafocal (Kapandji) pinning of unstable distal radius fractures: a preliminary report. Journal of Trauma and Acute Care Surgery. 1996; 40(2):194-198.

13. Parikh SN, Divatia PA, Parikh PN. Intrafocal (Kapandji) pinning of unstable distal radius fractures. Indian Journal 
International Journal of Orthopaedics Sciences

of Orthopaedics. 2003; 37(1):11.

14. Rosenthal AH, Chung KC. Intrafocal pinning of distal radius fractures: a simplified approach. Annals of plastic surgery. 2002; 48(6):593-599. 